\title{
Interactions between Ibuprofen and Silicified-MCC: Characterization, Drug Release and Modeling Approaches
}

\author{
Rudra Narayan Sahoo, ${ }^{1}$ Ashirbad Nanda, ${ }^{1}$ Arunima Pramanik, ${ }^{1}$ Souvik Nandi, ${ }^{1}$ \\ Rakesh Swain, ${ }^{1}$ Sukanta Kumar Pradhan ${ }^{2}$ and Subrata Mallickk,* \\ ${ }^{1}$ School of Pharmaceutical Sciences, Siksha 'O' Anusandhan (Deemed to be University), \\ Kalinganagar, Bhubaneswar- 751003, Odisha, India.
}

${ }^{2}$ Department of Bioinformatics, Orissa University of Agriculture and Technology, Bhubaneswar, Odisha, India.

*Corresponding author: E-mail: profsmallick@gmail.com

Fax: +91-674-2350642; Tel: +91-674-2350635

Received: 03-06-2019

Running Title: Docking analysis of ibuprofen with SMCC

\begin{abstract}
Analysis of the binding interactions of ibuprofen and silicified-microcrystalline cellulose (SMCC) has been undertaken. Co-processing of ibuprofen with SMCC was carried out by solid state ball milling, and aqueous state equilibration followed by freeze drying to investigate the effect of silicified-microcrystalline cellulose on ligand. Molecular docking study revealed that ibuprofen formed complex through hydrogen bond with microcrystalline cellulose (MCC) and silicon dioxide $\left(\mathrm{SiO}_{2}\right)$; the binding energy between $\mathrm{MCC}$ and $\mathrm{SiO}_{2}$, and ibuprofen and SMCC were found as -1.11 and -1.73 $\mathrm{kcal} / \mathrm{mol}$ respectively. The hydrogen bond lengths were varying from 2.028 to $2.056 \AA$. Interaction of Si atom of SMCC molecule with Pi-Orbital of ibuprofen has shown the bond length of $4.263 \AA$. Significant improvement in dissolution of ibuprofen has been observed as a result of interaction. Binary and ternary interactions revealed more stabilizing interactions with ibuprofen and SMCC compared to SMCC formation.
\end{abstract}

Keywords: Co-processing; silicified microcrystalline cellulose; molecular docking analysis; binary interaction; ternary interaction.

\section{Introduction}

Molecular docking experiment was used to predict the binding mode interactions between the molecules. ${ }^{1}$ The program uses Lamarckian genetic algorithm, semi empirical free energy force field, grid box based method to allow rapid evaluation of the binding energy and pre-calculating the interaction between every atom type pair at every distance and result clustering procedures. The force field is based on a comprehensive thermodynamic model that allows incorporation of intramolecular energies into the predicted free energy of the binding. ${ }^{2}$

Rheumatoid arthritis, a systemic inflammatory disease causes pain, stiffness, and swelling of joints and, over the time, the disease has a severe, chronic and invalid progression with loss of mobility. ${ }^{3,4}$ Ibuprofen could be consid- ered as the drug of choice in the management and therapy of inflammation in rheumatoid arthritis. ${ }^{5}$ Oral bioavailability of ibuprofen is very poor due to its poor water solubility. ${ }^{6}$ Low oral bioavailability limits therapeutic efficacy of the drug. ${ }^{7}$ Dissolution rate of ibuprofen (BCS class II) in gastrointestinal fluid is the rate limiting step in its oral absorption and often results in low and erratic oral bioavailability., Many techniques have been reported to improve the bioavailability of poorly water-soluble drugs. ${ }^{10,11}$ Solid state amorphization can achieve improved solubility. ${ }^{12}$

Microcrystalline cellulose is used in many solid oral dosage formulations in the pharmaceutical industry. Microcrystalline cellulose has outstanding compressibility properties and is commonly used in tablets. After silicification microcrystalline cellulose can improve binding capability and drug release as a material in tablet formula- 
tions by direct compression, wet granulation, dry granulation, and extrusion/spheronization processes. ${ }^{13-15}$ The present work was undertaken to analyze the binding interactions between ibuprofen and silicified-microcrystalline cellulose. Chemical structure of ibuprofen, silicon dioxide and microcrystalline cellulose is shown in Figure 1. Solid state ball milling, and aqueous state equilibration and freeze drying were the co-processing techniques applied to investigate the effect of silicified-microcrystalline cellulose on ligand. Interactions were monitored by FTIR, DSC and SEM followed by in vitro drug release studies. Molecular docking analysis of binary and ternary interactions would reveal stabilizing interactions of silicone dioxide-MCC (formation of SMCC) and ibuprofen-SMCC, which has not been found in extensive literature survey.

Infrared spectroscopy, a commanding technique gives a quantitative estimation of infrared intensity of absorption which is proportional to the magnitude of the change in the dipole moment of a bond during vibration. ${ }^{16,17}$ Drug-excipient interaction study in the solid state has been reported very recently without any co-processing (physical mixture) using infrared spectroscopy and DSC studies. ${ }^{16}$ Infrared spectroscopy results have been supported by differential scanning calorimetry (DSC) and scanning electron microscopy (SEM) in a report of drug excipient interaction study. ${ }^{18}$

AutoDock 4 programme was used to predict the binding mode interactions between ibuprofen as a ligand against MCC and silicon dioxide complex (SMCC). Docking calculations was performed with the grid box of the same size $[(40 \times 40 \times 40)]$ with different grid centre to find out the potential binding conformations between ibuprofen, MCC and silicon dioxide. The least binding energy scored conformations were considered as the best conformation. The detailed procedure of molecular docking (using AutoDock) was adopted from a recent study. ${ }^{19}$

\section{Experimental}

\section{1. Materials}

Ibuprofen, Colloidal Silicone Dioxide (Aerosil 200vv) was taken from Aristro Pharma as a gift sample, silicified microcrystalline cellulose were taken from Caplin Point, Chennai. All other chemical were used as analytical grade.

\section{2. Co-processing of Ibuprofen and Silicified Microcrystalline Cellulose}

Ibuprofen and silicified microcrystalline cellulose were mixed for 10 minutes by blending process using mortar and spatula at laboratory ambient condition $\left(\sim 30^{\circ} \mathrm{C}\right.$ and 60 $\% \mathrm{RH})$. Physical mixture of ibuprofen and silicified microcrystalline cellulose at weight ratio of 1:1 was co-processed by ball-milling in the dry state, and aqueous state kneading and freeze drying and tabulated presented in Table 1.

Table 1. Formulation of co-processing of ibuprofen with silicified microcrystalline cellulose

\begin{tabular}{ccc}
\hline $\begin{array}{c}\text { Formulation } \\
\text { code }\end{array}$ & $\begin{array}{c}\text { Ibu : SMCC } \\
\text { (by weight) }\end{array}$ & Co-processing \\
\hline $\mathrm{I}_{1} \mathrm{~S}_{1} \mathrm{P}$ & $1: 1$ & $\begin{array}{c}\text { Physical mixture } \\
\mathrm{I}_{1} \mathrm{~S}_{1} \mathrm{~B}\end{array}$ \\
$1: 1$ & $\begin{array}{c}\text { Dry- state ball milling } \\
\text { Aqueous state kneading } \\
\text { and freeze drying }\end{array}$ \\
$\mathrm{I}_{1} \mathrm{~S}_{1} \mathrm{~F}$ & $1: 1$ & a \\
\hline
\end{tabular}

(Ibuprofen $=$ Ibu; Silicified microcrystalline cellulose $=$ SMCC $)$

\section{3. Ball Milling}

The physical mixture of ibuprofen and silicified microcrystalline cellulose in the solid state was placed into the cylindrical vessel of ball mill (Swastik Electro and Scientific Work, India) and $1 \mathrm{~h}$ period of constant milling was done at lab ambient condition at $100 \mathrm{rpm}$ (Figure 2). The ball volume to the milling vessel volume was about $30 \%$ and milling was carried out using balls of 4, 8, 14 and $20 \mathrm{~mm}$ in diameter. The milling experiments with constant set-up of ball-to-physical mixture mass ratio of $25: 1$ was used. ${ }^{20}$

\section{4. Freeze - Drying}

Sufficient amount of distilled water was added in the physical powder mixture of ibuprofen and silicified microcrystalline cellulose to make slurry and kneaded well for a<smiles>CC(C)Cc1ccc(C(C)C(=O)O)cc1</smiles>

a)

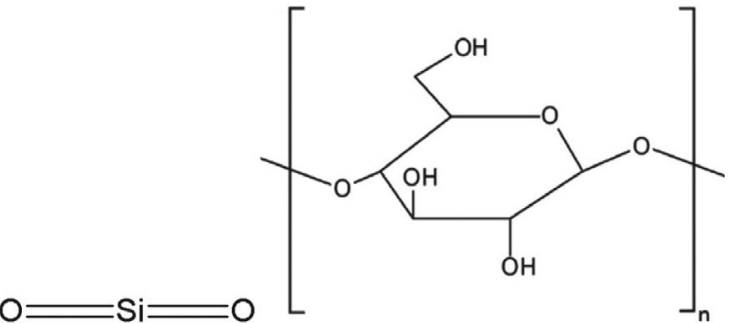

b) c)

Fig. 1. Chemical structure of (a) ibuprofen, (b) silicon dioxide, and (c) microcrystalline cellulose. 


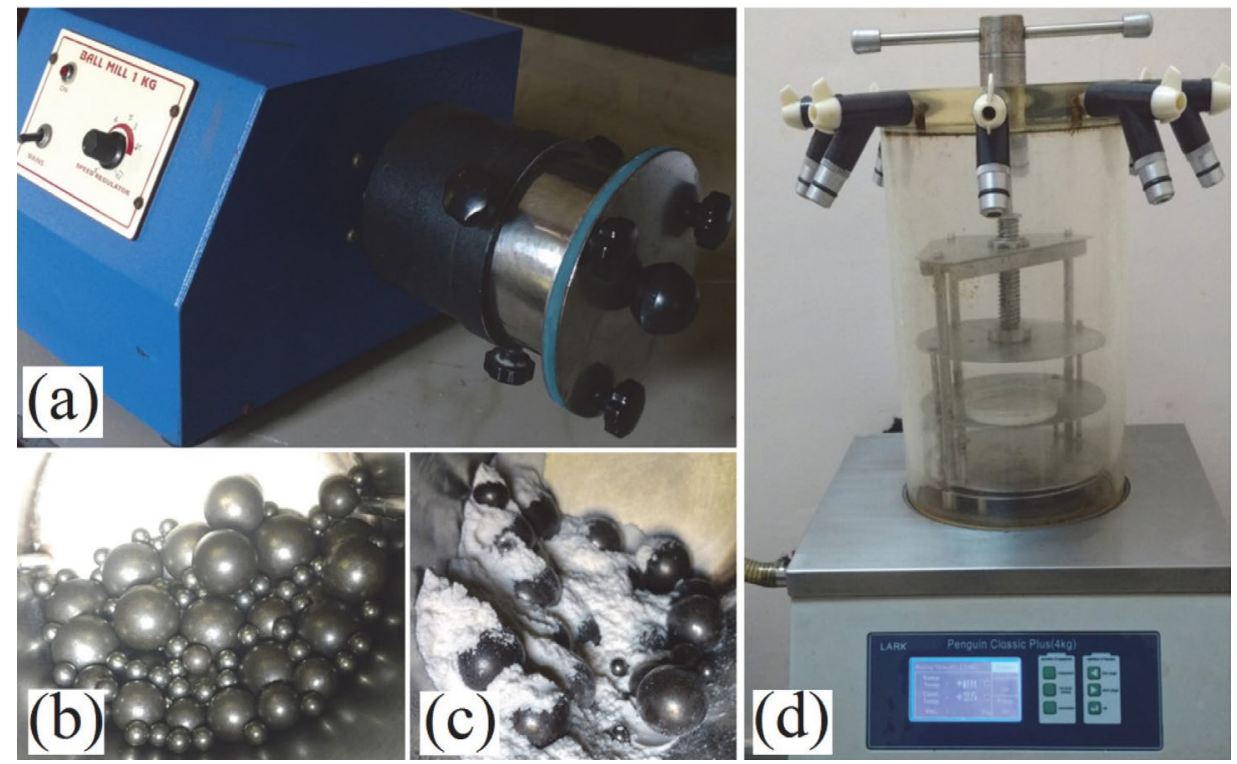

Fig. 2. Co-processing of ibuprofen with SMCC: (a) Laboratory Ball mill (1 kg) used for solid-state milling; (b) The balls charged for milling process; (c) Ibuprofen -SMCC physical mixture just after loading for the milling process; (d) Freeze dryer used for drying the physical mixer after aqueous state equilibration.

period of $30 \mathrm{~min}$. The slurry then placed in the dark for a period of about $12 \mathrm{~h}$ at room ambient condition for equilibration. The kneaded samples were freeze dried for 12 hours for effective drying using a laboratory vacuum freeze dryer $(4 \mathrm{~kg}, 220 \mathrm{~V})$ with attached vacuum $(220 \mathrm{~V}$, 2.7 A, 370W, $1400 \mathrm{rpm}, 50 \mathrm{~Hz}$ ) (Lark, Penguin Classic Plus, India). Temperature maintained at $-40{ }^{\circ} \mathrm{C}$ (approx.) and pressure during freeze-drying was adjusted to $15-20$ $\mathrm{Pa}$. The freeze dried samples were preserved in the desiccators till further analysis. The ball milled and freeze dried samples were placed at ambient condition for few hours and dried in an incubator (Labotech, India) at $50{ }^{\circ} \mathrm{C}$. The dried powder were passed through mesh 44 (opening $\sim 350 \mu \mathrm{m})$ and assayed for drug content determination from the absorbance measured at $222 \mathrm{~nm}\left(\lambda_{\max }\right)$ in the UV visible spectrophotometer (Jasco-V630 UV spectrophotometer).

\section{5. FTIR Study}

The FTIR spectra of pure ibuprofen and co-processed powder samples were performed for a comparative study between co-milling and co-freeze drying interaction. All the samples were thoroughly mixed with potassium bromide in the ratio $1: 100 . \mathrm{KBr}$ discs were prepared by compressing the powders at a pressure of 6 tons for the 10 min in a hydraulic pellet press (Technosearch Instruments, Maharashtra, India). FTIR spectrometer (FTIR-4100 type A, Jasco, Tokyo, Japan) was used for collecting all scans from $4000-400 \mathrm{~cm}^{-1}$ of 80 accumulations at a resolution of $4 \mathrm{~cm}^{-1}$ and scanning of $2 \mathrm{~mm} / \mathrm{s}$. Spectra manager for windows software (Jasco, Tokyo, Japan) was used for data acquisition and holding.

\section{6. Surface Morphology and Thermal Analysis of the Particle}

The surface morphology and crystalline nature of the particle samples were investigated by using Scanning Electron Microscope (Instrument: JSM-6390, Jeol, Tokyo, Japan). The dried samples were coated with gold and scanned at room temperature using voltage $10 \mathrm{kV}$ (Wd 19 and spot size 48). Downloaded Imagej software (https:// imagej.nih.gov/ij/download.html) was used for determining particle size distribution of the powder samples. Thermal behavior of powder samples were characterized by using Differential Scanning Calorimeter (DSC, Universal V4.2E TA Instrument). Powder samples approximately 2-4 mg were weighed accurately and put into crimped aluminum pans with a pin hole in the lid. All samples were heated at a heating rate of $10^{\circ} \mathrm{C} / \mathrm{min}$ in a nitrogen atmospheric condition up to $300^{\circ} \mathrm{C}$.

\section{7. In-vitro Dissolution Release}

Powdered samples containing $10 \mathrm{mg}$ equivalent of ibuprofen were dispersed in $900 \mathrm{ml}$ of distilled water and drug release was carried out using USP XXIV type II dissolution apparatus (Electrolab dissolution tester USP) at a temperature of $37 \pm 0.2{ }^{\circ} \mathrm{C}$ at an $\mathrm{rpm}$ of 100 . Ibuprofen concentration was determined by UV absorbance at 222 $\mathrm{nm}$. Samples were withdrawn at appropriate time intervals of $5,10,15,30,60,90$ and $120 \mathrm{~min}$, and replaced with a fresh dissolution medium. After proper rinsing of the $\mathrm{cu}-$ vette and filtration of the sample through a $0.45 \mu \mathrm{m}$ membrane filter, absorbance was recorded using the UV visible spectrophotometer. Standard calibration curve was used 
for calculating the respective concentration and the data were reported as the mean of not less than three determinations.

\section{8. Molecular Docking Analysis}

The molecular visualizations and interaction analysis was performed using Discovery studio visualizer (Acceleris Inc.). The 3-D Structure file of ibuprofen was downloaded from Drug Bank (ID: DB01050) as PDB format. The 3-D structures of silicon dioxide and MCC were drawn by using marvin sketch ${ }^{19,21}$ and saved as PDB extension files. The non-bonded $\mathrm{H}$-atoms were merged, Kollman united atom type charges and solvation parameters were added. The PDBQT files of ibuprofen, MCC and silicon dioxide were prepared with the help of Auto Dock tools programme. ${ }^{22}$ The ibuprofen non-steroidal anti-inflammatory drug was taken as a ligand to identify its binding affinity against the MCC and silicon dioxide complex (SMCC). In order to understand the interaction between MCC (receptor) with the ligand silicon dioxide another molecular docking experiment was carried out using these molecules. The docking complex stability was measured on the basis of binding constant and interaction energy.

\section{Results and Discussion}

The dry-state co-milling and aqueous state co-processing could be analogous to the commonly followed process in the tablet granulation department of pharmaceutical industries. Ball milling studies in different literature has shown different duration and speed of rotation. Median particle diameter has not been changed significantly upon milling of alfa-lactose monohydrate at a milling time of 60 and $300 \mathrm{~min}$ (ball-to-powder mass ratio of 25:1 and
13:1), and highest degree of amorphization was resulted at the ratio of $25: 1 .^{20}$ In another milling study increasing powder loading decreased milling efficiency at a given rotation speed of 50, 100, and $153 \mathrm{rpm} .{ }^{23}$ Hence, $1 \mathrm{~h}$ milling time and $100 \mathrm{rpm}$ of milling speed could be justifiable or closely resembling to the dosage form processing. These processes are simple, effective and scalable for interaction study. Due to presence of varying amount of bound moisture in the native silicified microcrystalline cellulose the milled material became moisty in nature and needed drying. Instant character of freeze dried sample is to absorb moisture like a sponge when left at ambient condition of $-60 \% \mathrm{RH}$ and $30^{\circ} \mathrm{C}$ for few hours and drying in an incubator at $50^{\circ} \mathrm{C}$ becomes necessary. The co-processed dried and equilibrated powder materials were passed through mesh of opening $\sim 350 \mu \mathrm{m}$ and assayed for actual drug content determination. Ibuprofen-silicified microcrystalline cellulose interaction study has been characterized by FTIR and the usefulness of this powerful technique has been supported by scanning electron microscopy and differential scanning calorimetry as described below. Drug release from the formulated dosage form is important and ultimately related to the bioavailability of the drug. Dissolution of ibuprofen from the co-processed material has also been described below.

\section{1. FTIR Analysis}

Spectral figure and data of FTIR band assignments of ibuprofen and co-processed samples are tabulated presented in Table 2 and Figure 3 respectively. FTIR spectrum of ibuprofen has shown medium to very strong band at 3094, 2958 and $2901 \mathrm{~cm}^{-1}$ assigned to $\mathrm{CH}_{2}$ asymmetric stretching, $\mathrm{CH}_{3}$ asymmetric stretching and $\mathrm{CH}_{2} \cdot \mathrm{CH}$ symmetric stretching respectively. Strong peaks in the region of 2800 $3000 \mathrm{~cm}^{-1}$ of ibuprofen are still present when co-milled in

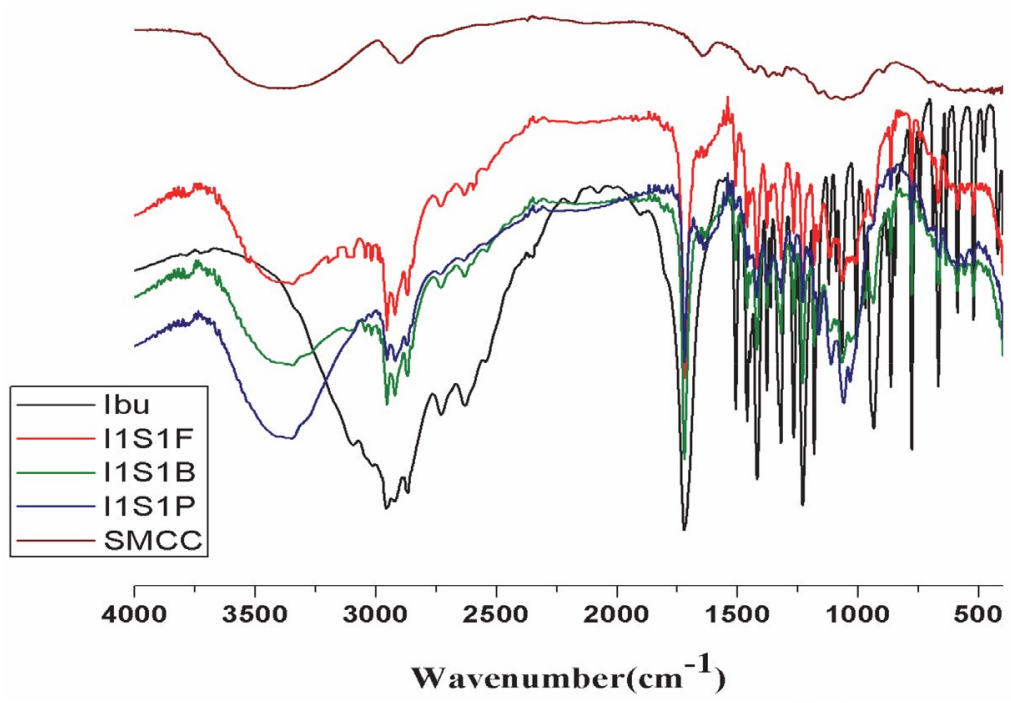

Fig. 3. FTIR Spectra of Ibuprofen co-processed with SMCC 
Table 2. Spectral data of FTIR band assignments of ibuprofen and co-processed samples.

\begin{tabular}{|c|c|c|c|c|c|c|}
\hline \multirow[b]{2}{*}{ Band } & \multirow[b]{2}{*}{ Tentative assignment } & \multicolumn{5}{|c|}{ Wave number $\left(\mathrm{cm}^{-1}\right)$} \\
\hline & & Ibuprofen & SMCC & $\mathrm{I}_{1} \mathrm{~S}_{1} \mathrm{~B}$ & $\mathrm{I}_{1} \mathrm{~S}_{1} \mathrm{~F}$ & $\mathrm{I}_{1} \mathrm{~S}_{1} \mathrm{P}$ \\
\hline 1 & $\mathrm{OH}$ stretching & Absent & $3200-3550 \mathrm{bb}$ & $3200-3550 \mathrm{bb}$ & $3200-3550 \mathrm{bb}$ & $3200-3550 \mathrm{bb}$ \\
\hline 2 & $\mathrm{CH}_{2}$ asym str & $3094 \mathrm{~m}$ & - & absent & absent & absent \\
\hline 3 & $\mathrm{CH}_{3}$ asym str & 2958 vs & - & 2955 vs & 2954 vs & 2955 vs \\
\hline 4 & $\mathrm{CH}_{2} \mathrm{CH}$ sym str & $2901 \mathrm{~s}$ & $2901 \mathrm{~s}$ & $2901 \mathrm{~s}$ & $2901 \mathrm{~s}$ & $2901 \mathrm{~s}$ \\
\hline 5 & $\mathrm{CH}_{2}$ sym str & $2868 \mathrm{~m}$ & - & $2868 \mathrm{~m}$ & $2869 \mathrm{~m}$ & $2868 \mathrm{~m}$ \\
\hline 6 & $\mathrm{O}-\mathrm{H}$... O valance str combination & $2729 \mathrm{~m}$ & - & $2730 \mathrm{~m}$ & $2730 \mathrm{~m}$ & $2728 \mathrm{~m}$ \\
\hline 7 & O-H...O valance str combination & $2630 \mathrm{~m}$ & - & $2629 \mathrm{~m}$ & $2629 \mathrm{~m}$ & $2629 \mathrm{~m}$ \\
\hline 8 & $\mathrm{C}=\mathrm{O}$ str & 1722 vs & - & 1721 vs & 1720 vs & 1722 vs \\
\hline 9 & conjugated $\mathrm{C}=\mathrm{O}$ stretching mode & Absent & $1645 \mathrm{~s}$ & $1645 \mathrm{~m}$ & $1645 \mathrm{~m}$ & $1645 \mathrm{~m}$ \\
\hline 10 & aromatic $\mathrm{C}=\mathrm{C}$ str & $1507 \mathrm{~s}$ & - & $1508 \mathrm{~s}$ & $1510 \mathrm{~s}$ & $1507 \mathrm{~s}$ \\
\hline 11 & $\mathrm{CH}_{3}$ asym deformation, $\mathrm{CH}_{2}$ scissoring & $1462 \mathrm{~s}$ & - & $1461 \mathrm{~s}$ & $1461 \mathrm{~s}$ & $1461 \mathrm{~s}$ \\
\hline 12 & $\mathrm{CH}-\mathrm{CO}$ deformation & $1420 \mathrm{~s}$ & - & $1420 \mathrm{~s}$ & $1422 \mathrm{~s}$ & $1420 \mathrm{~s}$ \\
\hline 13 & $\mathrm{CH} 3$ sym str & $1380 \mathrm{~s}$ & - & $1379 \mathrm{~s}$ & $1378 \mathrm{~s}$ & $1379 \mathrm{~s}$ \\
\hline 14 & $\mathrm{OH}$ in plane deformation & $1321 \mathrm{~s}$ & - & $1321 \mathrm{~s}$ & $1321 \mathrm{~s}$ & $1321 \mathrm{~s}$ \\
\hline 15 & $=\mathrm{C}-\mathrm{H}$ in plane deformation & $1268 \mathrm{~s}$ & - & $1267 s$ & $1267 \mathrm{~s}$ & $1268 \mathrm{~s}$ \\
\hline 16 & C...C str & 1230 vs & - & 1231 vs & 1231 vs & 1231 vs \\
\hline 17 & C-O str & $1183 \mathrm{~s}$ & - & $1183 \mathrm{~s}$ & $1183 \mathrm{~s}$ & $1183 \mathrm{~s}$ \\
\hline 18 & $\mathrm{Si}-\mathrm{O}-\mathrm{Si}$ asym str & Absent & $1059 \mathrm{bb}$ & $1066 \mathrm{bb}$ & $1059 \mathrm{bb}$ & $1075 \mathrm{bb}$ \\
\hline 19 & C-O-C str & $970 \mathrm{~m}$ & - & - & - & Absent \\
\hline 20 & $\mathrm{C}-\mathrm{H}$ out of plane vibration & $866 \mathrm{~s}$ & - & $865 \mathrm{~s}$ & $866 \mathrm{~s}$ & $866 \mathrm{~s}$ \\
\hline 21 & $\mathrm{CH}_{2}$ rocking & $779 \mathrm{~s}$ & - & $780 \mathrm{~s}$ & $780 \mathrm{~s}$ & $779 \mathrm{~s}$ \\
\hline 22 & $\mathrm{CH}_{2}$ in plane rocking & $522 \mathrm{~m}$ & - & $521 \mathrm{~m}$ & $521 \mathrm{~m}$ & $521 \mathrm{~m}$ \\
\hline 23 & O-Si-O bending & Absent & $451 \mathrm{bb}$ & $461 \mathrm{bb}$ & $461 \mathrm{bb}$ & $451 \mathrm{bb}$ \\
\hline
\end{tabular}

(s- strong; bb- broad band; mbb- medium broad band; w- weak; sym-symmetrical; asym-asymmetrical; str-stretching; m- medium; vs- very strong; vw - very weak; vvw - very very weak; aa- almost absent.)

the dry-state as well as co-freeze-dried after aqueous state kneading and equilibration with silicified microcrystalline cellulose assigned to the characteristic symmetric and asymmetric stretching vibrations of alkyl chain. High intensity carbonyl peak at $1722 \mathrm{~cm}^{-1}$ of ibuprofen became very weak after co-processing in the solid-state as well as wet-state with silicified microcrystalline cellulose. ${ }^{24}$ The band at $1645 \mathrm{~cm}^{-1}$ of silicified microcrystalline cellulose designated to conjugated $\mathrm{C}=\mathrm{O}$ in the aldehyde on the terminal anhydro-glucose unit is also present in co-processed samples. A strong $\mathrm{CH}_{2}$ rocking vibration band is noticed at $779 \mathrm{~cm}^{-1}$ in ibuprofen and the intensity observed to be weaker and weaker after co-processing. $\mathrm{CH}_{2}$ in plane rocking vibration $\left(522 \mathrm{~cm}^{-1}\right)$ is identified in pure ibuprofen and became weaker when co-milled and freeze dried after co-kneading. C-O stretching at $1183, \mathrm{CH}_{2}$ scissoring vibration at 1462 and $\mathrm{CH}-\mathrm{CO}$ deformation at $1420 \mathrm{~cm}^{-1}$ contributed their occurrence strongly in ibuprofen alone and weakly in the co-processed sample. A big broad band between 3200 to $3550 \mathrm{~cm}^{-1}$ attributed to the presence of the $\mathrm{O}-\mathrm{H}$ stretching frequency of silanol group bonded to the inorganic structure of containing $\mathrm{SiO}_{2}$ (SMCC), and also hydrogen bonds between adsorbed water and silanol. ${ }^{25}$ This bulky broad band is not present in ibuprofen pure drug but consistently maintained in all the co-processed formulations might be due to intermolecular hydrogen bonding. The band related to the Si-O-Si (silanol) asymmetric stretching was found at $1059 \mathrm{~cm}^{-1}$ with elevated intensity in SMCC and also in the co-processed materials. Another peak at $451 \mathrm{~cm}^{-1}$ due to O-Si-O bending notably observed in the formulations. The small changes in the band orientation, band intensity and overlapping indicated only Vander Waals or dipole-dipole interactions between ibuprofen and silicified microcrystalline cellulose molecules.

\section{2. SEM and DSC}

Scanning electron microscopy is a commanding tool for examining the inhibition of crystal growth morphology. Figure 4 shows distinctive plate like geometric layers of the initial samples of pure ibuprofen indicating crystalline nature. Slightly damaged morphology of the crystal geometry of ibuprofen is seen in the physical mixture of $1: 1$ ratio of $\mathrm{I}_{1} \mathrm{~S}_{1} \mathrm{P}$ in presence of fine particles of SMCC. Crystal geometry of ibuprofen has been damaged appreciably after co-milling in the solid-state and cofreeze-drying after aqueous state kneading and equilibration with silicified microcrystalline cellulose. The Feret diameter and its distribution of the powder sample were evaluated opening the SEM image (Figure 5). Feret diameter is an estimate of a particle size along a specified direction and can be defined as the distance between the two parallel planes restricting the particle perpendicular to 

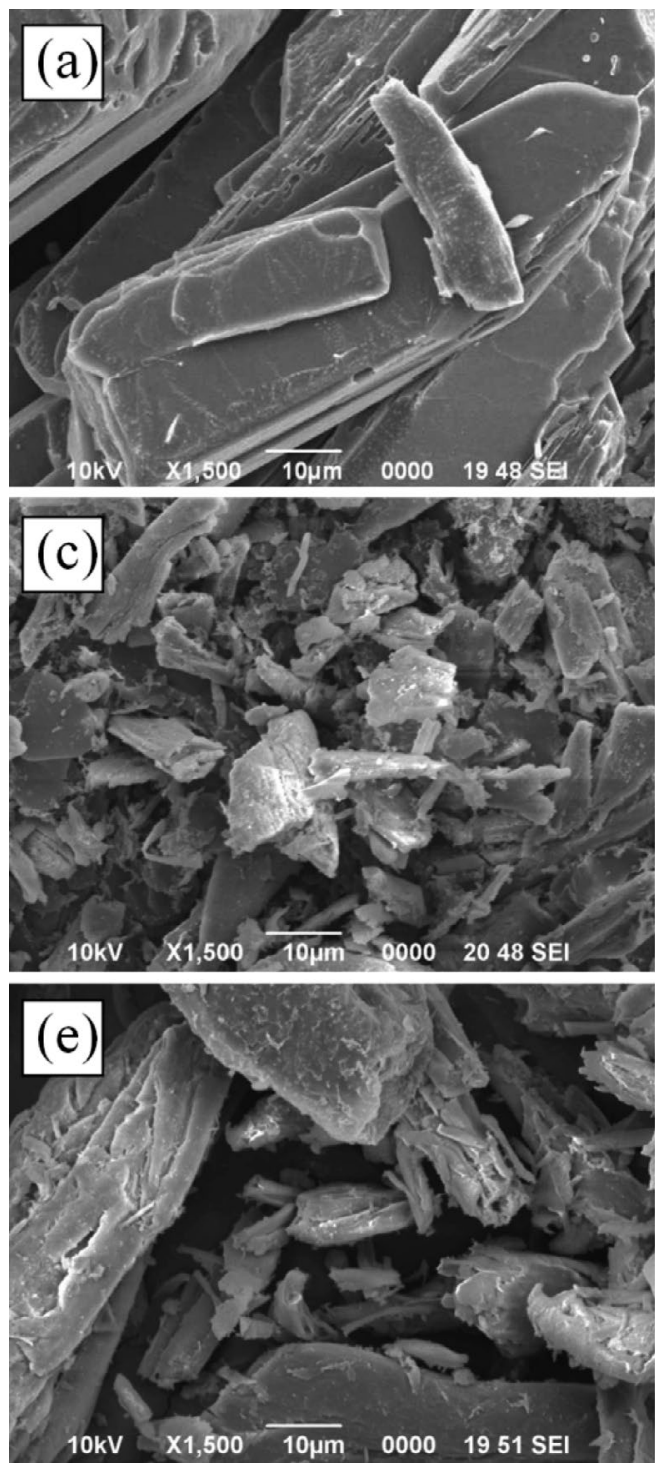

Fig. 4. SEM Images (a) Ibu; (b) $I_{1} S_{1} P$; (c) and (d) $I_{1} S_{1} B$; (e) and (f) $I_{1} S_{1} F$.

that direction. In both cases $\left(\mathrm{I}_{1} \mathrm{~S}_{1} \mathrm{~B}\right.$ and $\left.\mathrm{I}_{1} \mathrm{~S}_{1} \mathrm{~F}\right)$ particle size has been significantly reduced. Irregular particles in agglomerated and discrete forms are prominently seen after co-processing. These noticeable changes in morphology may be due to amorphization of ibuprofen to the large extent.

Differential scanning calorimetry is frequently used in pharmaceutical research as an analytical tool for the identification and interaction study of active drug after co-processing with other pharmaceutical compounds. It can explain the miscibility/incompatibility with its effects on thermal stability, yielding results promptly and efficiently. ${ }^{26}$ Thermograms after differential scanning calorimetry of pure ibuprofen and co-processed powder samples are depicted in Figure 6. Pure ibuprofen has shown the melting endotherm at $76.66^{\circ} \mathrm{C}$ which is approximately similar to the literature value. ${ }^{27}$ The peak, onset and
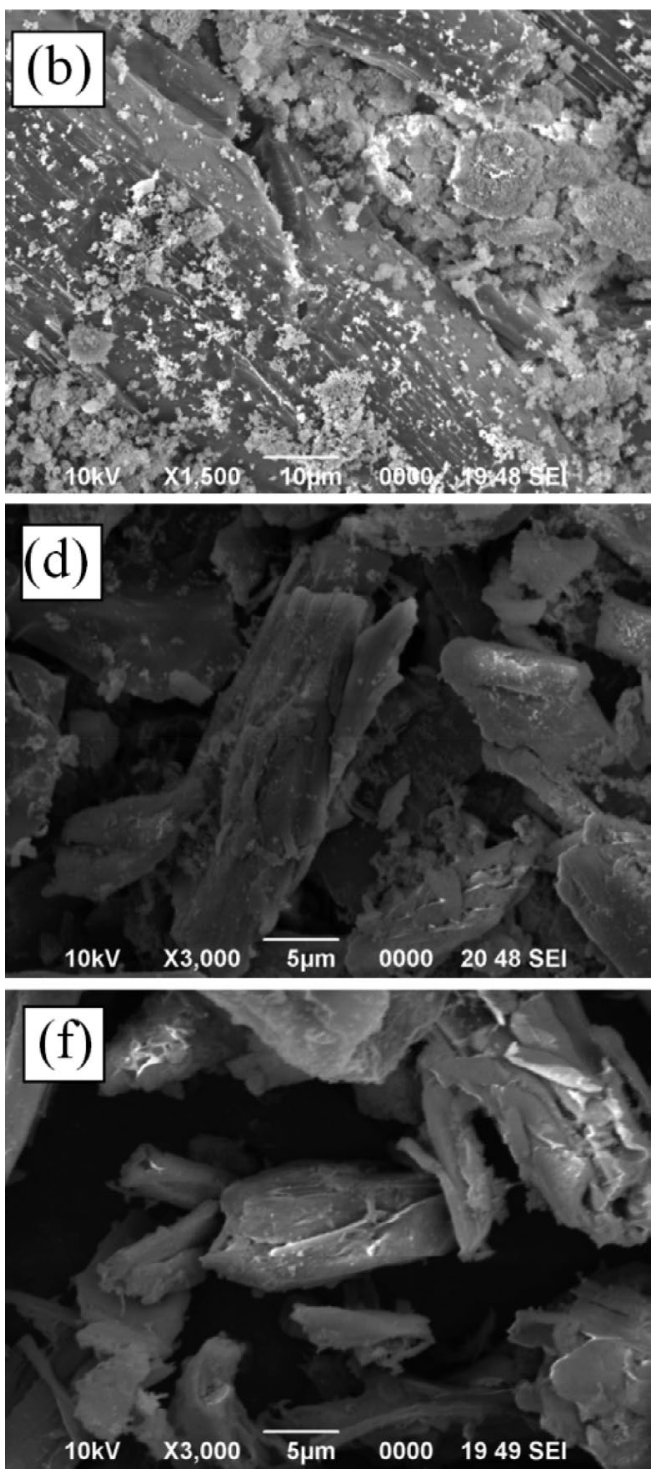

endset of melting of ibuprofen in the formulated powder samples have not been changed significantly (Table 3 ) but the enthalpy of melting (normalized, $\mathrm{J} / \mathrm{g}$ ) of ibuprofen $(-322.55)$ decreased drastically after co-processing and that is the indication of amorphous transformation of ibuprofen in the co-processed formulations. Solid-state ball-milling sample exhibited lesser enthalpy content $(-42.93)$ compared to freeze-dried material (-63.40). This result suggested that the extent of amorphization of ibuprofen is more in $\mathrm{I}_{1} \mathrm{~S}_{1} \mathrm{~B}$ rather than $\mathrm{I}_{1} \mathrm{~S}_{1} \mathrm{~F}$ material (relative crystallinity 13.31 and $19.66 \%$ respectively with reference to pure drug ibuprofen). The physical mixture has shown only $22.49 \%$. The zero crystallinity corresponds to a totally amorphous particle. In our present work relative crystallinity (\%) has been shown with reference to the pure drug ibuprofen which is highly crystalline (reference). 
a)

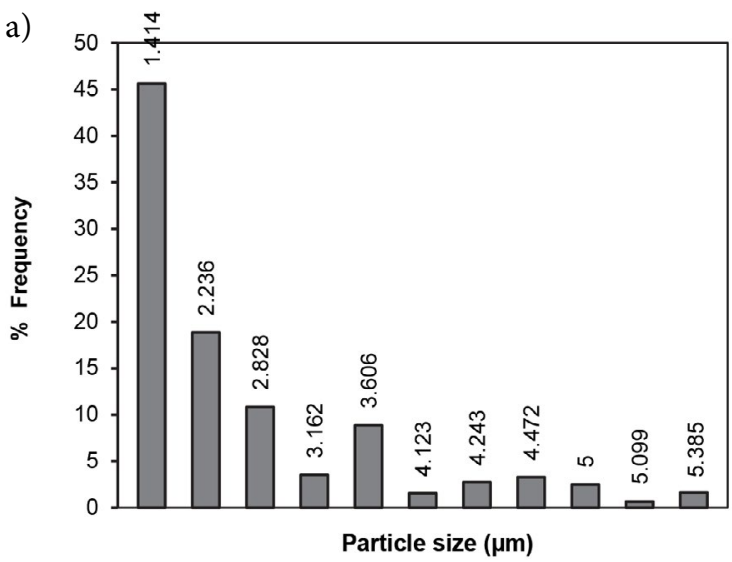

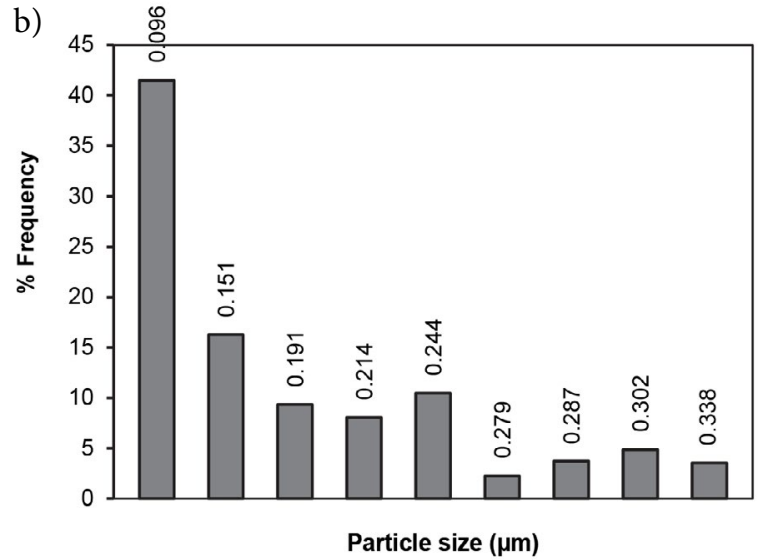

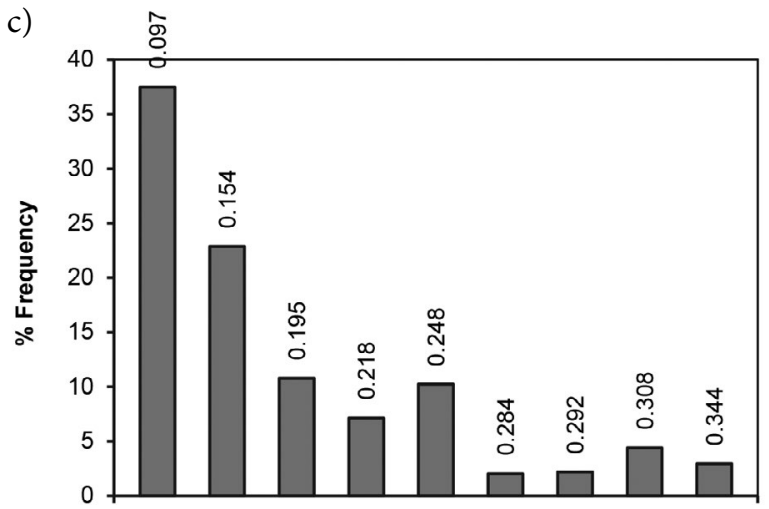

Particle size $(\mu \mathrm{m})$

Fig. 5. Feret diameter and its distribution of the powder sample estimated from SEM image: (a) Ibu, (b) $I_{1} S_{1} F$, (c) $I_{1} S_{1} B$.

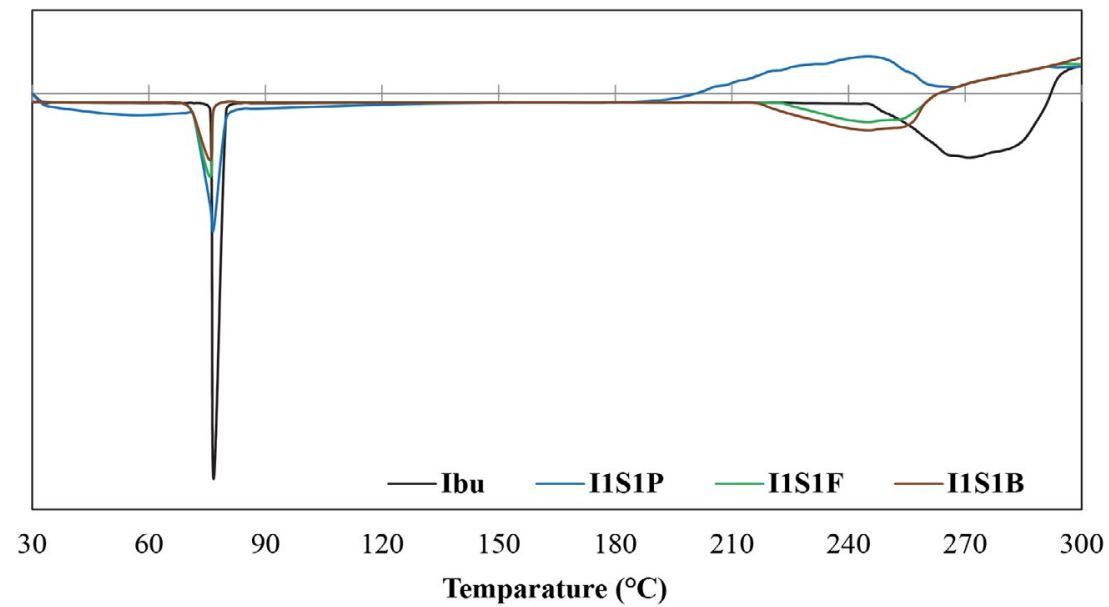

Fig. 6. DSC Thermogram of ibuprofen co-processed with SMCC.

Table 3. Thermal analysis after co-processing of ibuprofen with microcrystalline cellulose

\begin{tabular}{cccccc}
\hline Formulation & $\begin{array}{c}\text { Peak } \\
\text { melting }\left({ }^{\circ} \mathbf{C}\right)\end{array}$ & $\begin{array}{c}\text { Onset } \\
\text { melting }\left({ }^{\circ} \mathbf{C}\right)\end{array}$ & $\begin{array}{c}\text { End set } \\
\text { melting }\left({ }^{\circ} \mathbf{C}\right)\end{array}$ & $\begin{array}{c}\text { Normalized } \\
(\mathbf{J} / \mathbf{g})\end{array}$ & $\begin{array}{c}\text { Relative } \\
\text { crystallinity (\%) }\end{array}$ \\
\hline $\mathrm{Ibu}$ & 76.66 & 75.78 & 79.93 & -322.55 & Reference \\
$\mathrm{I}_{1} \mathrm{~S}_{1} \mathrm{P}$ & 76.56 & 73.03 & 80.43 & -72.53 & 22.49 \\
$\mathrm{I}_{1} \mathrm{~S}_{1} \mathrm{~B}$ & 74.71 & 73.04 & 76.34 & -42.93 & 13.31 \\
$\mathrm{I}_{1} \mathrm{~S}_{1} \mathrm{~F}$ & 75.66 & 73.03 & 77.99 & -63.40 & 19.66 \\
\hline
\end{tabular}




\section{3. In-vitro Drug Release}

Many research reports used distilled water ${ }^{28-30}$ as media to determine the solubility of drug substance. Ibuprofen drug release from microemulsion was studied also in distilled water by $\mathrm{Hu}$ et al..$^{31}$ Ibuprofen release profiles were similar for three kinds of microspheres in distilled water and with solution of low $\mathrm{pH}$ of 1.2 because of poor solubility of the drug. ${ }^{32}$ Like ibuprofen many other non-steroidal anti-inflammatory drugs tend to self-associate by forming mixed-charged micelles or micelle-like structures and the solubility-pH profiles cannot be described properly with the Henderson-Hasselbalch eq. ${ }^{33,34}$ However, release of ibuprofen in distilled water will give an idea about its overall improvement in dissolution. Figure 7 shows cumulative percentage release of ibuprofen in distilled water of the co-processed material up to $120 \mathrm{~min}$. The powder materials have shown significantly improved dissolution of drug after co-processing. Comparison of two dissolution profiles is based on the determination of a model independent statistical method, the difference factor $f_{1}$ and the similarity factor $f_{2}$. Similarity or equivalence between two dissolution profiles is based on $f_{1} \leq 15$ and $f_{2}$ $\geq 50 .{ }^{35-37}$ Significantly improved drug dissolution of solid state milling, and aqueous state kneading and freeze drying has been understood by using $f_{1}$ and $f_{2}$ values when pair wise formulation vs pure drug was compared $\left(f_{1}\right.$ : $32.75, \& f_{2}: 13.29$ and $f_{1}: 15.05, \& f_{2}: 28.93$ respectively). Crystalline ibuprofen exhibited only $52.89 \%$ dissolution whereas, dry-state co-milling and freeze dried co-processed material has improved dissolution to a great extent (85.84 and $81.35 \%$ respectively). Silicified microcrystalline cellulose has shown more impact in solid state milling compared to aqueous state kneading and equilibration and brought about more amorphization of ibuprofen. As a result more improved dissolution has been achieved in ball milled product. ${ }^{38}$

Drug release mechanism has been predicted to develop a rational formulation utilizing mathematical models. The drug release data was analyzed by applying different kinetic models as First order, Higuchi, Korsmeyer-Peppas kinetics $^{39,40}$ using Origin Pro 8.0 (Originlab Corporation, US) software by non-linear regression analysis. These models are represented as follows:

First order model: $Q=100-\exp \left(\left(-K_{F} * t\right)+4.605\right)$
Higuchi model: $Q=K_{H} \times \sqrt{t}$

Korsmeyer-Peppas model: $Q=K_{p} \times t^{n}$

$Q=$ Cumulative percent drug release at time $t$

$K_{F}=$ First order release rate constant

$K_{H}=$ Higuchi release rate constant,

$K_{P}=$ Parameter reflecting the structural and geometric characteristics of the delivery device, or Peppas release rate constant,

$n$ = Power law exponent, or release exponent.

This $n$ value indicates drug release controlled by Fick's laws and also confirmed by the Higuchi model. Matrix controlled release has been followed (Figure 8). The kinetic parameters as per model are presented in the Table 4. As per Peppas model, $n$ value 0.5 is referred to Fickian release pattern. The $n$ value of $\mathrm{I}_{1} \mathrm{~S}_{1} \mathrm{P}, \mathrm{I}_{1} \mathrm{~S}_{1} \mathrm{~F}$ and $\mathrm{I}_{1} \mathrm{~S}_{1} \mathrm{~B}$ was found to be $0.400,0.408$ and 0.143 respectively (less than 0.5 ) which indicated the diffusion controlled release mechanism. The diffusion controlled release mechanism has also been supported by the fitting of Higuchi model $\left(R^{2}\right.$ is 0.354-0.973).

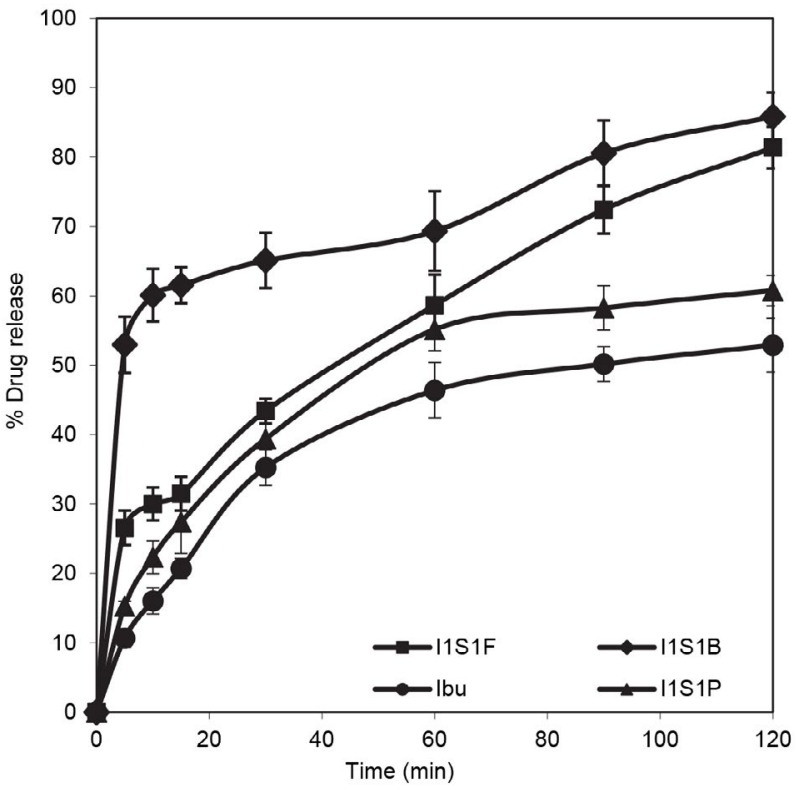

Fig. 7. Cumulative percentage release profiles of ibuprofen co-processed with SMCC.

Table 4. Model fitting and kinetic parameters of drug dissolution of ibuprofen co-processed material.

\begin{tabular}{|c|c|c|c|c|c|c|c|c|c|c|c|c|}
\hline \multirow[t]{2}{*}{ Formulation } & \multirow[t]{2}{*}{$f_{1}$} & \multirow[t]{2}{*}{$f_{2}$} & \multicolumn{2}{|c|}{ First order } & \multirow[b]{2}{*}{$R S S$} & \multicolumn{2}{|c|}{ Higuchi } & \multirow[b]{2}{*}{ RSS } & \multicolumn{3}{|c|}{ Korsmeyer-Peppas } & \multirow[b]{2}{*}{ RSS } \\
\hline & & & $\begin{array}{c}K_{F} \\
\left(\mathrm{~min}^{-1}\right)\end{array}$ & $r^{2}$ & & $\begin{array}{c}K_{H} \\
\left(\% . \min ^{-1 / 2}\right)\end{array}$ & $r^{2}$ & & $n$ & $K_{P}$ & $r^{2}$ & \\
\hline $\mathrm{I}_{1} \mathrm{~S}_{1} \mathrm{P}$ & 6.25 & 48.96 & 0.011 & 0.789 & 727 & 6.27 & 0.956 & 150 & 0.400 & 9.544 & 0.976 & 69 \\
\hline $\mathrm{I}_{1} \mathrm{~S}_{1} \mathrm{~F}$ & 15.04 & 28.93 & 0.017 & 0.854 & 729 & 7.71 & 0.973 & 133 & 0.408 & 11.363 & 0.990 & 40 \\
\hline $\mathrm{I}_{1} \mathrm{~S}_{1} \mathrm{~B}$ & 32.75 & 13.28 & 0.07 & 0.466 & 2590 & 9.52 & 0.354 & 3131 & 0.143 & 41.497 & 0.986 & 54 \\
\hline
\end{tabular}

$\mathrm{RSS}=\operatorname{Sum}$ of $\left(\mathrm{Q}_{\mathrm{exp}}-\mathrm{Q}_{\text {calc }}\right)^{\wedge} 2$ 
a)

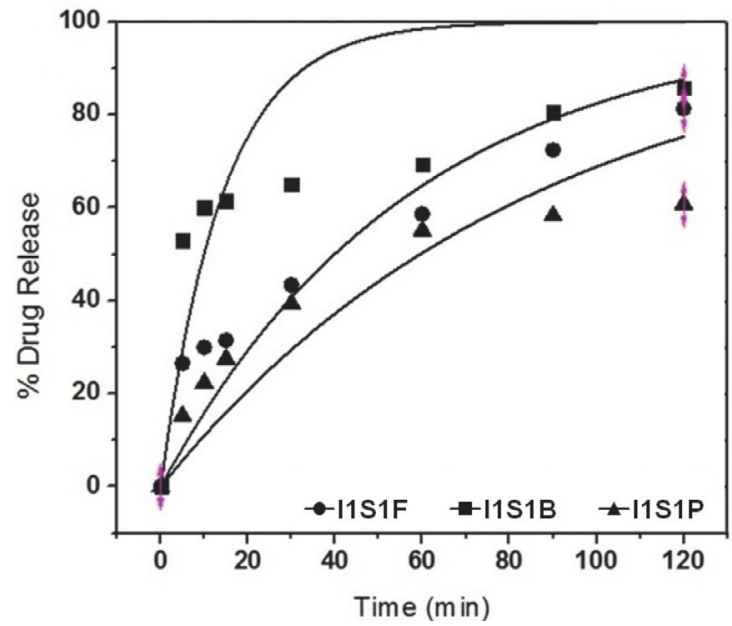

b)

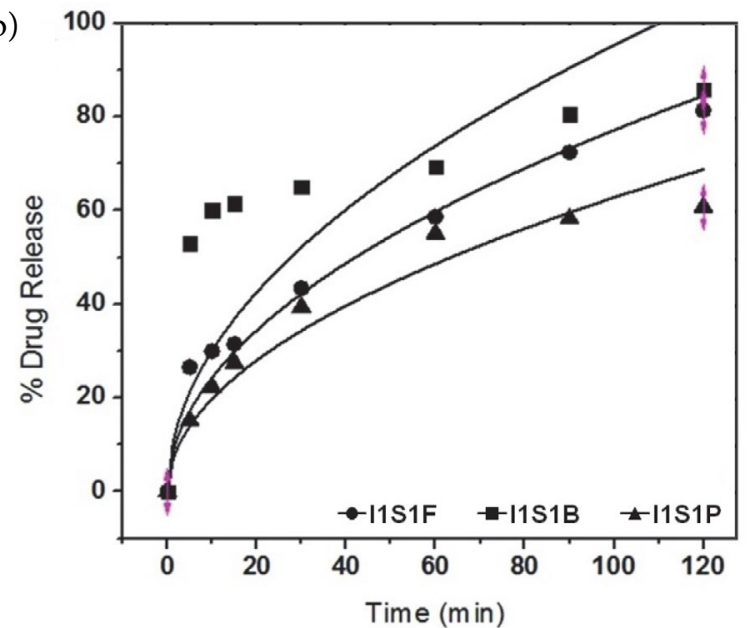

c)

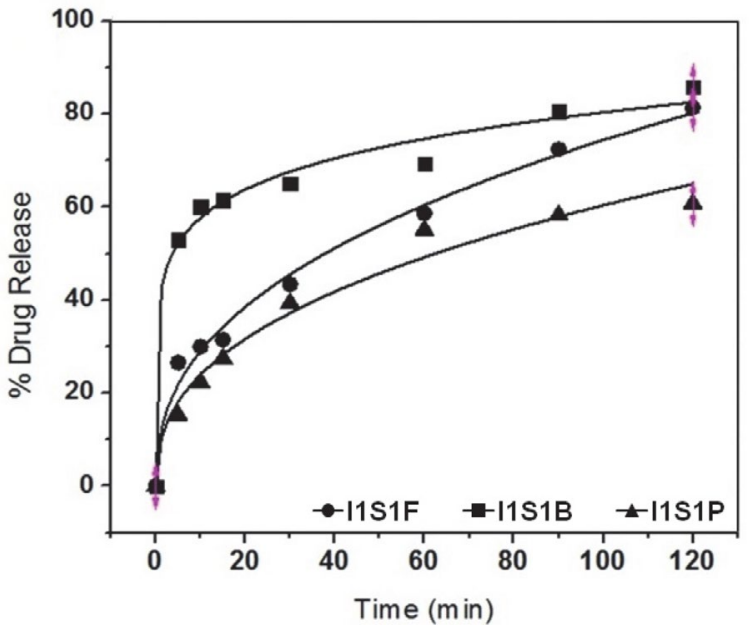

Fig. 8. Kinetics of drug release applying kinetic models to plot both the experimental data (symbols) and the models (curves): (a) First order (b) Higuchi (c) Korsmeyer-Peppas.

\section{4. Molecular Docking Analysis of the Complexes}

The predicted co-ordinates of ibuprofen and silicone dioxide complex were monitored by molecular docking method Table 5 and Figure 9 respectively. The interaction between $\mathrm{MCC}-\mathrm{SiO}_{2}$ would be obtained from inter molecular hydrogen bonding between $\mathrm{OH}$ group of $\mathrm{MCC}$ and $\mathrm{H}$ atom of $\mathrm{SiO}_{2}$. The hydrogen bond lengths are varying from
2.028 to $2.056 \AA$ Á. The binding energy value was found $-1.11 \mathrm{kcal} / \mathrm{mol}$. Hydrogen bonding plays a vital role in H-bonded network systems. Hydrogen bond length between ibuprofen and SMCC are ranging from 2.028 to $2.930 \AA \AA$ and the most interesting other probable interaction of Si atom of SMCC molecule with Pi-Orbital of ibuprofen showing bond length of 4.263 Á. The binding energy was found to be $-1.73 \mathrm{kcal} / \mathrm{mol}$. The higher negative binding energy values indicate stable interactions than

Table 5. Molecular docking and binding parameter interactions in the co-processing of ibuprofen with silicified microcrystalline cellulose

\begin{tabular}{lcccc}
\hline $\begin{array}{l}\text { Binding } \\
\text { Molecules }\end{array}$ & $\begin{array}{c}\text { Binding energy } \\
(\mathbf{K c a l} / \mathbf{m o l})\end{array}$ & $\begin{array}{c}\text { Binding } \\
\text { atoms }\end{array}$ & Bond name & $\begin{array}{c}\text { Bond } \\
\text { length }(\AA)\end{array}$ \\
\hline $\mathrm{MCC}-\mathrm{SiO}_{2}$ & -1.11 & $\mathrm{OH} \mathrm{---} \mathrm{O}$ & Hydrogen Bond & 2.028 \\
(SMCC) & & $\mathrm{H} \mathrm{---} \mathrm{O}$ & Hydrogen Bond & 2.056 \\
$\mathrm{SMCC}-\mathrm{Ibuprofen}$ & -1.73 & $\mathrm{OH} \mathrm{---} \mathrm{O}$ & Hydrogen Bond & 2.028 \\
& & $\mathrm{OH} \mathrm{---} \mathrm{O}$ & Hydrogen Bond & 2.930 \\
& & $\mathrm{H} \mathrm{---} \mathrm{O}$ & Hydrogen Bond & 2.056 \\
& & $\mathrm{Si} \mathrm{---} \mathrm{Pi-orbital}$ & Pi-Sulfur Bond & 4.263 \\
\hline
\end{tabular}


a)

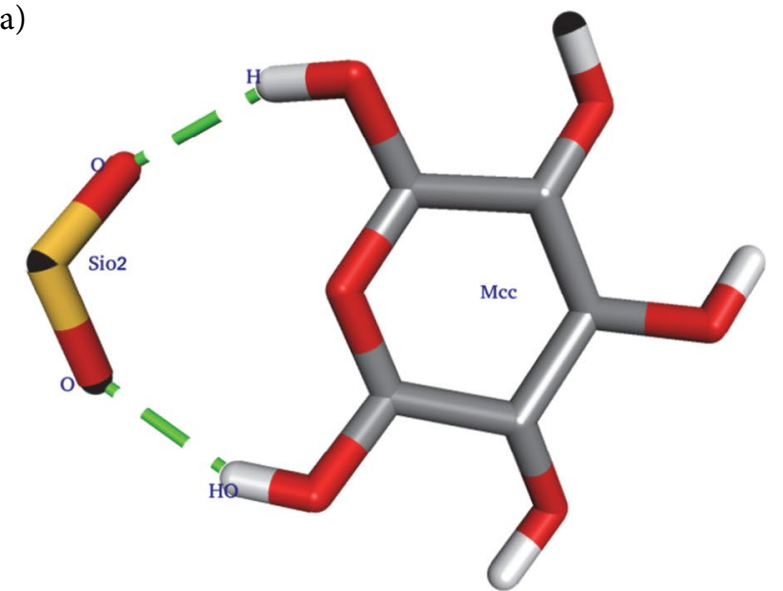

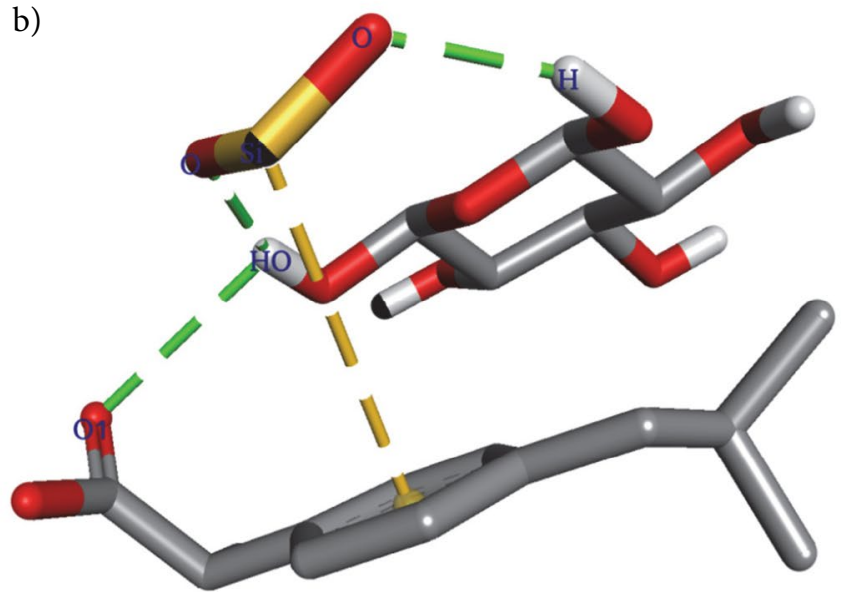

Fig. 9. Molecular docking study of (a) SMCC (binary); and (b) ibuprofen-microcrystalline cellulose -silicon dioxide (ternary).

that of lower negative values, which indicate destabilizing interactions. ${ }^{21,41}$

\section{Conclusions}

Binding interactions of ibuprofen and silicified-microcrystalline cellulose (SMCC) has been analysed. The drystate and aqueous state co-processing of ibuprofen was performed by co-milling and co-freeze-drying after aqueous state kneading and equilibration with silicified microcrystalline cellulose in at laboratory scale to investigate the effect of silicified-microcrystalline cellulose on ligand. The changes in the band intensity, band orientation, and overlapping of FTIR indicated only the H-bond, Van der Waals and/or dipole-dipole interactions between ibuprofen and silicified microcrystalline cellulose molecules. SEM study revealed that the ibuprofen crystal morphology has been damaged appreciably after co-processing in the solid-state and wetstate with SMCC. Thermal analysis has shown significantly decreased enthalpy of melting of ibuprofen after co-processing with SMCC. Silicified microcrystalline cellulose has transformed more amorphization of ibuprofen by solid state milling compared to aqueous state kneading and freeze drying and brought about more improved dissolution of ibuprofen of ball milled product rather than freeze dried product. Matrix controlled release mechanism has been predicted utilizing mathematical kinetic models. Molecular docking study revealed the formation of ibuprofen complex through hydrogen bonding with MCC and silicon dioxide. The binding energy between $\mathrm{MCC}$ and $\mathrm{SiO}_{2}$, and ibuprofen and SMCC were found as -1.11 and $-1.73 \mathrm{kcal} / \mathrm{mol}$ respectively.

\section{Acknowledgements}

The authors are acknowledging gratefulness to the Department of Science \& Technology, Ministry of Science \& Technology, New Delhi, India, for providing INSPIRE fel- lowship to Rudra Narayan Sahoo (IF 150987). The authors are also very much grateful to Prof. Manoj Ranjan Nayak, President, Siksha O Anusandhan (Deemed to be University) for providing other facilities and encouragement.

\section{Conflicts of interest}

The authors declare that there is no conflict of interest.

\section{References}

1. W. P. Sohtun, A. Kannan, K. Hari Krishna, D. Saravanan, M. S. Kumar, M. Velusamy, Acta Chim. Slov. 2018, 65, 621-629. DOI:10.17344/acsi.2018.4275

2. G. M Morris, R. Huey, W. Lindstrom, M. F. Sanner, R. K. Belew, D. S. Goodsell, A. J. Olson, J. Comput. Chem. 2009, 16, 2785-2791. DOI:10.1002/jcc.21256

3. P. O. Carvalho, Q. B. Cass, S. A. Calafatti, F. J. Contesini, R. Bizaco, Braz. J. Chem. Eng. 2006, 23(03), 291-300. DOI:10.1590/S0104-66322006000300003

4. T. Chaban, V. V. Ogurtsov, V. S. Matiychuk, G. Chaban, L. Demchuk, A. Nektegayev, Acta Chim. Slov. 2019, 66, 103111. DOI: $10.17344 /$ acsi.2018.4570

5. Q. Wei, H. Yuanzhi, G. Zhen, L. Zhang, W. Li, Y. Xianzhen, S. Shakya, A. Maharjan, T. Yan, Z. Weifeng, Z. Jiwen, Asian J. Pharm. Sci. 2018, 4, 1-9.

6. M. Mombeini, G. Saki, L. Khorsandi, N. Bavarsad, Medicina, 2018, 54(1), 1-9. DOI:10.3390/medicina54010001

7. R. Lobenberg, G. L Amidon, Eur. J. Pharm. Biopharm. 2000, 50(1), 3-12.

8. R. P. Swain, B. B. Subudhi, Drug. Dev. Ind. Pharm. 2019, (Published online: 16 Feb 2019).

DOI:10.1080/03639045.2019.1572183

9. S. Mallick, S. Pattnaik, K. Swain, P. K. De, Drug Dev. Ind. Pharm. 2007, 33, 535-541. DOI:10.1080/03639040601050130

10. S. Mallick, S. Pattnaik, K. Swain, P. K De, A. Saha, G. Ghoshal, A. Mondal, Drug Dev. Ind. Pharm. 2008, 34, 726-734. DOI:10.1080/03639040801901868 
11. S. Mallick, A. Sahu, K. Pal, Acta Pol. Pharm. 2004, 61, 21-30.

12. R. H. Dave, Overview of Pharmaceutical Excipients used in tablets and capsules, https://www.drugtopics.com/hospitalhealth-system-pharmacy/overview-pharmaceutical-excipients-used-tablets-and-capsules, (assessed: March 13, 2019).

13. S. Lijun, L. Liping, S. Xiaoying, C. Honglang, Z. Shumin, C. Wenfeng, Z. Ruoxia, Z. Wenchang, Asian J. Pharm. Sci. 2018, 19(13), 1-10.

14. R. Vasluianu, D. A. Forna, M. Zaltariov, A. Murariu, Rev. Chim. (Bucharest). 2016, 67(12), 2475-2478.

15. M. S. Bhandari, S. M. Wairkar, U. S. Patil, N. R. Jadhav, Acta Chim. Slov. 2018, 65, 492-501. DOI:10.17344/acsi.2017.3822

16. F. Dragan, I. Kacso, S. Dreve, F. Martin, G. Borodi, I. Bratu, K. Earar, Rev. Chim. (Bucharest). 2015, 66(2), 191-195.

17. B. Tita, G. Furau, E. Marian, D. Tita, C. Furau, Rev. Chim. (Bucharest). 2016, 67(4), 706-710.

18. E. Marian, T. Jurca, B. Tita, P. Sfirloaga, D. Tita, N. Duteanu, Rev. Chim. (Bucharest). 2015, 66(4), 477-481.

19. J. Maharana, M. C. Patra, B. C. De, B. R. Sahoo, B. K. Behera, S. De, S. K Pradhan, J. Mol. Recog. 2014, 27(5), 260-275. DOI:10.1002/jmr.2357

20. S. Pazesha, J. Grasjo, J. Berggren, G. Alderborn, Int. J. Pharm. 2017, 528, 215-227.

DOI:10.1016/j.ijpharm.2017.05.043

21. R. Mohapatra, S. Mallick, A. Nanda, R. N. Sahoo, A. Pramanik, A. Bose, D. Das, L. Pattnaik, RSC Adv. 2016, 6, 3197631987. DOI:10.1039/C6RA03604J

22. G. M. Morris, D. S. Goodsell, R. S. Halliday, R. Huey, W. E. Hart, R. K. Belew, A. J. Olson, J. Comput. Chem. 1998, 19(14), 1639-1662. DOI:10.1002/(SICI)1096-987X(19981115)19:14 $<1639:: A I D-J C C 10>3.0 . C O ; 2-B$

23. H. Shin, S. Lee, H. S. Jung, J. Kim, Ceram. Int. 2013, 39(8), 8963-8968. DOI:10.1016/j.ceramint.2013.04.093

24. S. Mallick, S. K. Pradhan, R. Mohapatra, Int. J. Biol. Macromol. 2013, 60, 148-155. DOI:10.1016/j.ijbiomac.2013.05.021

25. A. L. Balieiro, R. A. Santos, M. M. Pereira, R. T. Figueiredo, L. S. Freitas, O. L. S. de Alsina, A. S. Lima, C. M. F. Soares, Braz. J. Chem. Eng. 2016, 33(2), 361-372.

DOI:10.1590/0104-6632.20160332s20140089
26. B. Panda, A. S. Parihar, S. Mallick, Int. J. Biol. Macromol. 2014, 67, 295-302. DOI:10.1016/j.ijbiomac.2014.03.033

27. S. Mallick, S. K. Pradhan, M. Chandran, M. Acharya, T. Digdarsini, R. Mohapatra, Results Pharm. Sci. 2011, 1(1), 1-10. DOI:10.1016/j.rinphs.2011.05.003

28. P. Arya, K. Pathak. Int J Pharm. 2014, 460(1-2), 1-12. DOI:10.1016/j.ijpharm.2013.10.045

29. F. L. Mota, A. P. Carneiro, A. J. Queimada, S. P. Pinho, E. A. Macedo. Eur J Pharm Sci. 2009, 37(3-4), 499-507.

DOI:10.1016/j.ejps.2009.04.009

30. F. A. Maulvi, S. J. Dalwadi, V. T. Thakkar, T. G. Soni, M. C. Gohel, T. R. Gandhi. Powder Technol. 2011, 207(1-3), 47-54. DOI:10.1016/j.powtec.2010.10.009

31. L. Hu, J. Yang, W. Liu, L. Li, Drug Deliv. 2011, 18(1), 90-95, DOI:10.3109/10717544.2010.522613

32. Q. Wei, Asian J. Pharm. Sci. 2019, 14, 174-182. DOI:10.1016/j.ajps.2018.05.003

33. A. Avdeef, ADMET DMPK. 2014, 2(1), 33-42. DOI:10.5599/admet.2.1.30

34. A. Fini, Int. J. Pharm. 1995, 126(1-2), 95-102. DOI:10.1016/0378-5173(95)04102-8

35. P. Costa, J. Manuel, S. Lobo, Eur. J. Pharm. Sci. 2001, 13, 123 133. DOI:10.1016/S0928-0987(01)00095-1

36. A. Pramanik, R. N. Sahoo, A. Nanda, R. Mohapatra, R. Singh, S. Mallick, Curr. Eye Res. 2018, 43(6), 828-838. DOI:10.1080/02713683.2018.1446534

37. D. Vetchy, M. Vetcha1, M. R. Artina, E. Gryczova, L. Bartošikova, Medicina, 2007, 43(4), 326-330.

DOI:10.3390/medicina43040040

38. S. Mallick, S. Pattnaik, K. Swain, P. K. De, Drug Dev. Ind. Pharm. 2007, 33(8), 865-873.

DOI:10.1080/03639040701429333

39. S. Mallick, K. Roy, A. Saha, Acta Pol. Pharm. 2002,59(3), 193198.

40. S. Mallick, B. K. Gupta, S. K. Ghoshal, J. Sci. Ind. Res. 1999, 58, 1010-1016.

41. A. Nanda, R. N. Sahoo, A. Pramanik, R. Mohapatra, S. K. Pradhan, A. Thirumurugan, D. Das, S. Mallick, Colloids Surf. B Biointerfaces. 2018, 172, 555-564.

DOI:10.1016/j.colsurfb.2018.09.011

\section{Povzetek}

Opravili smo analizo veznih interakcij med ibuprofenom in silicificirano mikrokristalno celulozo (SMCC). Procesiranje ibuprofena s SMCC je bilo izvedeno z mletjem kroglic v trdnem stanju in ravnotežjem v vodni fazi, čemur je sledilo sušenje z zamrzovanjem. Želeli smo raziskati vpliv silificirane mikrokristalne celuloze na ligand. Z metodo molekulskega sidranja (»molecular docking«) smo pokazali, da ibuprofen tvori kompleks preko vodikove vezi z mikrokristalno celulozo (MCC) in silicijevim dioksidom $\left(\mathrm{SiO}_{2}\right)$; izračunana energija vezave med $\mathrm{MCC}$ in $\mathrm{SiO}_{2}$ ter ibuprofenom in SMCC je bila $\mathrm{kot}-1,11 \mathrm{kcal} / \mathrm{mol}$ oziroma $-1,73 \mathrm{kcal} / \mathrm{mol}$. Dolžine vodikovih vezi so se gibale od 2,028 ̊̊ do $2,056 \AA$. Interakcije atoma Si SMCC molekule s $\pi$-orbitalmi ibuprofena smo zaznali na razdalji 4,263 $\AA$. Kot rezultat interakcij smo opazili pomembno izboljšanje raztapljanja ibuprofena. Binarne in ternarne interakcije so pokazale bolj stabilne interakcije $\mathrm{z}$ ibuprofenom in SMCC v primerjavi s samo silificirano mikrokristalno celulozo (SMCC).

Except when otherwise noted, articles in this journal are published under the terms and conditions of the Creative Commons Attribution 4.0 International License 